Вестник ПСТГУ

I: Богословие. Фрилософия

2014. Bun. 4 (54). C. 97-108
Геннадий Анатольевич Џелковский, cm. преподаватель кафедры культурологии Института философского образования и науки Национального педагогического университета им. М. П. Драгоманова genats $2 @$ gmail.com

\title{
ЛИНГВИСТИЧЕСКИЕ КОРНИ РЕЛИГИОВЕДЕНИЯ
}

\author{
Г. А. ЦЕЛКовский
}

\begin{abstract}
Автор поднимает вопрос о влиянии лингвистики на формирование религиоведческих методологий и теорий. Религиозные парадигмальные изменения касаются следующих новых теорий в лингвистике: сравнительной методологии, структурализма и когнитивной лингвистики. Именно эти три подхода были ключевыми для возникновения и обновления религиоведения. Автор ставит вопрос, почему именно лингвистика выступила источником таких глобальных изменений в методологии религиоведения. Ключевым аспектом автор видит расширенное понимание языка в его отношении к религии. Взаимодействие языка и религии позволяет ученым исследовать религиозные явления через призму исследования языковых явлений. Моделями взаимоотношений языка и религии являются: религия как языковое явление; религия как продукт языковых процессов; религия и язык гомологичны; религия формируется лингвистическими инструментами. Выявление этих моделей взаимоотношений языка и религии в теоретическом изучении религии позволит нам понять историю религиоведения в соответствии с развитием языкознания. Автор показал, что проблема соотношения языка и мышления конституировала связь лингвистики и религиоведения. Она объединяет в себе все языковые теории религии: натурмифологическую, структуралистскую и когнитивную. Автор последовательно показывает основные достижения каждой теории. Сравнительно-историческое языкознание порождает сравнительное религиоведение и натурмифологическую теорию. Структурная лингвистика и семиотика раскрывают знаково-символическую природу религии и ее коммуникативный характер. Когнитивистика показывает процесс категоризации и концептуализации религиозного опыта. Становление экстралингвистики позволит религиоведению вычленить новые предметы исследования в религиоведении, такие как связь религиозного языка и религиозной группы (этнолингвистика и социолингвистика), или выявление особенностей религиозного опыта (психолингвистика).
\end{abstract}

Язык является символическим руководством к пониманию культуры

Эдвард Сепир

Общепринято связывать возникновение религиоведения с именем Фридриха Макса Мюллера - немецко-английского лингвиста, переводчика и теолога. Но связь религиоведения с филологией и лингвистикой оказалась не простым пересечением, случайно сложившимся при возникновении религиоведения, а принципиально существенным союзом, определившим всю историю науки о 
религии. И речь идет не только о необходимости классического филологического образования для историков религии ${ }^{1}$, а о парадигмальных сдвигах в религиоведении, причиной которых была лингвистика.

Автор выделяет следующие лингвистические повороты в религиоведении появление сравнительного религиоведения, структурная антропология и семиотика религии, когнитивное религиоведение. Кроме того, есть менее значительные проекты, но которые также оказали большое влияние на понимание феномена религии - герменевтика религии, Боасовская школа (гипотеза лингвистической относительности Сепира-Уорфа), дискурс-анализ, интерпретативная антропология К. Гирца и т.д. Интересный нюанс заключается в том, что между идеями М. Мюллера, А. Потебни и когнитивным религиоведением можно провести прямую параллель², в обоих случаях поднимаются проблемы связи религиозного сознания и процессов языкового и образного мышления. Яблоков ${ }^{3}$, например, выделяет мифолого-лингвистическую группу теорий, центральными в которой являются концепции Мюллера и Леви-Стросса.

\section{Взаимодействия языка и религии}

Понять методологическую роль лингвистики в изучении религии невозможно без понимания того, как рассматривается религия в лингвистической методологии, каким образом такая методология оказалась эффективна в религиоведении и как, в принципе, оказался возможным такой переход от одной науки К другой. Говоря о том, что необходимо раскрыть понимание религии лингвистикой, следует признать, что необходимо тогда раскрыть, как понимается язык в таких переходах. Иными словами, если исследовательское поле лингвистики расширяется таким образом, что включает в себя предметы изучения религиоведения, как возможно, что она все равно остается в пределах своего объекта, то есть языка?

Отвечая на этот вопрос, можно наметить несколько вариантов понимания связи религии и языка. Первый вариант - это идея гомогенности языка и религии. В этом случае они рассматриваются как родственные культурные явления, которые развиваются по сходным законам, и выработка новой методологии по изучению одного явления позволяет перенести данную методологию на другое явление.

Второй вариант предполагает рассмотрение генетической связи языка и религии, когда одно является продуктом другого, то есть религия признается продуктом языковых процессов или язык признается продуктом религиозных процессов (что, в принципе, возможно в теологическом контексте).

Третий вариант более культурологичен, и связан он с пониманием религии и религиозных явлений как языковых явлений в широком смысле, то есть как

\footnotetext{
${ }^{1}$ Как, например, указывает Фр. Хайлер. Цит. по: Самарина T. С. Методологические основы религиоведческого исследования в концепции Фр. Хайлера // Вестник ПСТГУ I: Богословие. Философия. 2014. Вып. 1 (45). С. 57-71.

${ }^{2}$ См.: Шахнович M. М. Когнитивная наука и исследования религии // Государство, религия и церковь в России и за рубежом. 2013. № 3. С. 32-63.

${ }^{3}$ См.: Яблоков И. Н. Религиоведение: Учеб. пособие. М., 2004. С. 195-210.
} 
коммуникативных и знаково-символических систем. Причем не акты коммуникации в религии вертикального и горизонтального уровней (Человек - Сверхъестественное, Человек - Общество), а сама религия предстает как когнитивная система, которая заключает в себе знания о посюстороннем и потустороннем мирах и транслирует их последующим поколениям.

Четвертый вариант связан с лингвистическим поворотом в философии и рождением аналитической философии религии, для которой анализ языка религии является смыслообразующей парадигмой. Но важно понимать, что язык религии в аналитической традиции философствования предстает как совокупность религиозных утверждений, а сама религия рассматривается как система таких утверждений. Здесь язык религии предстает перед нами как логическая система религиозных утверждений, которая может иметь как когнитивный характер (А. Плантинга, Д. Уолтерсторф), так и нонкогнитивный (А. Айер, Д. 3. Филипс $)^{4}$.

В свою очередь, пятый вариант связан с континентальной традицией герменевтической феноменологии М. Хайдеггера, для которого и язык, и религия это форма существования человека.

Последний, шестой вариант имеет не общеметодологический характер, а конкретно научный, и связан он с непосредственными языковыми явлениями в самой религии, которые являются частными проблемами филологии или лингвистики. Такими проблемами являются: анализ и критика священных текстов; закономерности функционирования священных, богослужебных и религиозных языков; религиозные социолекты и этнолекты; связь этноса, языка и религии; природа и характер религиозных символов, знаков; метафорическая и метонимическая природа мифов и ритуалов; проблема перевода и т. п.

Вышеуказанные варианты не исчерпывают весь спектр взаимодействия лингвистики и религиоведения, так как лингвистический поворот середины XX столетия предлагает во всем видеть язык.

\section{Возникновение сравнительного религиоведения}

Середина XIX столетия ознаменовалась большими открытиями в области сравнительного языкознания, а именно: открытие родственности санскрита и европейских языков (о. Паулиниус, Фр. Бопп), переводы индийских и персидских священных текстов на немецкий, французский и английский языки (У. Джонс, Ч. Уилкинс, Э. Бюрнуфф). Открытие общего корня индийских и европейских языков привело к выявлению индоевропейской языковой семьи. Параллельно этому в Германии, России, Скандинавии шло сравнительное изучение европейской дохристианской мифологии и мифологий древних цивилизаций - Египта, Вавилона, Рима и Греции.

${ }^{4} \mathrm{O}$ проблеме познаваемости религиозного языка см.: Plantinga $A$. The Warrant Christian Belief. N. Y., 2000; Walterstorf N. Divine Discourse: Philosophical Reflections on the Claim that God Speaks. Oxford, 1997; Ayer A. The Problem of Knowledge. L., 1956; Philips D. Z. Religion without Explanation. Oxford, 1977. 
Интенция европейских исследований на выявление праязыка и прамифологии восходит еще к эпохе Возрождения, когда встал вопрос о естественном откровении, более древнем и присущем человечеству вне исторического контекста и которое могло быть обнаружено в природных явлениях, закономерностях или, наоборот, в выпадающих из закономерностей явлениях ${ }^{5}$. Но оформление таких поисков в философскую парадигму произошло только в философии Нового времени - в поисках естественного человека (Ж.-Ж. Руссо), естественного языка (Ш. Монтескье), естественной религии (Г. Чезбери, Д. Юм).

K XIX столетию лингвистика обрела свою методологию и свой объект историческое сравнение языков. Язык, вслед за немецкими романтиками и И. Г. Гердером, признавался носителем народного (национального) духа. Гердер предлагает: «Философское сравнение было бы наилучшим опытом истории и разнообразной характеристики человеческого рассудка и души, в каждом языке есть отпечаток рассудка и характера народа» ${ }^{6}$. Ему вторит В. Гумбольдт: «Язык тесно переплетен с духовным развитием человечества и сопровождает его на каждой ступени его локального прогресса или регресса, отражая в себе каждую стадию культуры» ${ }^{7}$ Изучение языка позволяло ученым выйти к пониманию духовных процессов человечества, в том числе и религии.

Поскольку христианство выступало для немецких романтиков приобретенной, а не врожденной культурной формой, то исследователи и будители немецкой нации обратились к дохристианскому пласту верований и обрядов германо-скандинавской мифологии, которая имела аутентичный характер. Для гейдельбергских романтиков связь германской мифологии, немецкого языка с индийской религией и арийским языком позволяла обосновать немецкую национальную идею древности и исключительности, что в конечном счете отразилось в «Речах к немецкому народу» Фихте.

Почва для Макса Мюллера, сына немецкого романтика Вильгельма Мюллера, была готова - это и идея сравнительного исторического изучения языков, связь мифологии и языка, переживание бесконечного (влияние Фр. Шлейермахера). В принципе, М. Мюллеру досталось сделать заключительный шаг со сравнительной лингвистики выйти на сравнительную мифологию, что он как великий ученый и переводчик и сделал. В работе «Наука о языке» Мюллер пишет: «Ученые пренебрегали возможностью сравнивать как равнозначные языки, мифологии, эпосы германцев, готов, галлов с такими же явлениями эллинов и римлян» ${ }^{8}$. Таким образом, сравнительное религиоведение стало возможным благодаря пониманию генетической связи языка и религии по первому варианту: рассмотрению религии как продукта языковых процессов - в случае с ранним этапом Мюллера, деградационистских процессов, что вылилось в пе-

5 Элиаде в классической работе «Ностальгия по истокам» показывает такую преемственность между появлением религиоведения и эзотерическими поисками ученых эпохи Возрождения (см.: Элиаде М. Ностальгия по истокам. М., 2006).

${ }^{6}$ Гердер И. Г. Идеи к философии истории. М., 1977. С. 239.

${ }^{7}$ Гумбольдт В. О различии строения человеческих языков и его влиянии на духовное развитие человечества // Избранные труды по языкознанию. М., 2000. С. 48.

${ }^{8}$ Muller F. M. Three Lectures on the Science of Language and its Place in the General Education delivered at the Oxford University Extension Meeting. Chicago, 1899. P. 48. 
чально известную формулу «мифология - болезнь языка». Тенденция рассматривать мифологию как существенную часть религии восходит к романтикам (Крейцер).

Важным достижением Мюллера является идея сходства природы речи и религии как врожденных свойств человеческой природы ${ }^{9}$. Для Мюллера симптоматично проведение аналогий между мифологией, религией и языком: «способность верить» сравнивается с «даром речи»; сравнительный метод выводится из сравнительной филологии, которую он подчеркивает, перефразируя популярный афоризм Гете: «Кто знает один язык, тот не знает ни одного» в: «Кто знает одну религию, тот не знает ни одной". ${ }^{10}$.

Классификация религий по М. Мюллеру также имеет лингвистический характер. Открытие языковых групп не могло не привести к вопросу о культурном своеобразии принадлежащих к ним народов ${ }^{11}$. Для того чтобы постулировать религиозные особенности языковых групп, Мюллер должен был обосновать такую взаимосвязь между историческими формами религий и историческими языками. В первую очередь Мюллер обращает внимание на имена богов в соответствующих группах. Для арийских народов характерным является почитание богов в природе - молнии, тучи и т. д, на что указывают имена богов - Дьяус, Зеус, Один, Перун, Перкунас ${ }^{12}$. Особенностью туранских народов является почитание неба - Тиен, и для семитских народов характерно почитание силы, моральности богов - Элохим.

Именно первый этап научного творчества М. Мюллера был тесно связан с языковедением и филологией. Непосредственно прямые отсылки к сравнительному языковедению порождают сравнительное религиоведение; идею о врожденном свойстве человека переживать бесконечное, так же как врожденной является способность к речи; идею, что мифология - продукт языковых деградационистских процессов и тесно связана с особенностями первобытного мышления ${ }^{13}$; лингвистическая классификация религий, которая задала последующим поколениям религиоведов почву для критического осмысления классификаций и типологий религии.

${ }^{9}$ Мюллер $Ф$. М. Введение в науку о религии. Четыре лекции, прочитанные в Лондонском Королевском институте в феврале-марте 1870 года. М., 2002. С. 22.

${ }^{10}$ См.: Там же. С. 20.

${ }^{11}$ Фр. Боас, основатель американской антропологии, формулирует прямую взаимосвязь между языком и культурой, что выразилось в знаменитой гипотезе его учеников - Э. Сепира и Б. Уорфа. Гипотеза лингвистической относительности прямо признает язык детерминантом человеческого знания о мире, культурного своеобразия и т. д. (см.: Языки как образ мира. М.; СПб., 2003).

${ }^{12}$ Характерной в этом аспекте является работа последователя М. Мюллера Германа Узенера «Имена богов»(Usener H. Götternamen. Bonn, 1896). Кроме того, в таком духе написаны работы целой плеяды выдающихся российских филологов и историков - Ф. Буслаева, А. Афанасьева, О. Миллера, Л. Воеводского.

${ }^{13}$ Идея, имеющая далеко идущие последствия в виде целого направления философии языка и психологии языка, а именно в работах А. Потебни, Л. Леви-Брюля, Л. Выготского, А. Лурия, К. Леви-Стросса и т. д. 
Романтическая идея о деградации языка ${ }^{14}$ и, следовательно, «мифологии как болезни языка» стала отправной точкой для критики Мюллера Александром Потебней. Во-первых, как указывает Потебня, сомнителен тезис о совершенстве праязыка и постепенном «затемнении» мышления. Во-вторых, Мюллер противоречит сам себе, говоря, что язык развивается от конкретных именований к абстрактным. Каким же тогда образом абстрактные именования получают реальное бытие?!

Сам Потебня предлагает идею метафорической природы мифологии ${ }^{15}$. Языковые явления - метафоры, синекдохи, метонимии - призваны объяснить происхождение мифа, но, в отличие от Мюллера, Потебня видит в этом не упадок языка, а естественное обогащение культуры.

\section{Структуралистский подход}

Основатель семиологии как науки Фердинанд де Соссюр предвидел расширенное использование лингвистики: «Поскольку она (семиология. не существует, нельзя сказать, чем она будет, но она имеет право на существование, и ее место определено заранее... Благодаря этому не только прольется свет на проблемы лингвистики, но, как мы полагаем, при рассмотрении обрядов, обычаев и т. п. как знаков все эти явления также выступят в новом свете, так что явится потребность объединить их все в рамках семиологии и разъяснить их законами этой науки» ${ }^{16}$.

А «Первобытное мышление» Л. Леви-Брюля вернуло религиоведение и антропологию к проблеме человеческого сознания и особенностям его функционирования в разные исторические эпохи. Клод Леви-Стросс, дискутируя с концепцией Леви-Брюля, разрывает социологизаторский редукционизм функционалистов в объяснении религиозных явлений и выводит связь между религиозными или мифологическими явлениями по принципу структурной схожести всех культурных явлений. Отталкиваясь от идей Р. Якобсона и Ф. де Соссюра, Леви-Стросс рассматривает мифологию, религиозные ритуалы как языковые продукты. Ключевое отличие от предыдущих исследователей религии (имеются в виду функционалисты) заключается в том, что религиозные явления не содержанием, а системой внутренних отношений (структурой) отражают социальную реальность. Это можно выразить формулой: A[B] = C[D], где А и В - социальные явления, а С и D - мифо-ритуальные явления ${ }^{17}$. Собственно, Леви-Стросс так и называет свои разделы структурной (структуральной) антропологии: «Язык и общество» и «Лингвистика и антропология», где в первом разделе указывает на уникальные свойства языка как отправного пункта для исследования социальных явлений: «Из всех общественных явлений, видимо, только язык может подвергаться истинно научному исследованию, объясняющему способ его фор-

\footnotetext{
${ }^{14}$ Имеющая христианский характер, поскольку, по Библии, все современные языки являются искаженными вариантами эдемского праязыка.

${ }^{15}$ См.: Потебня А. А. Слово и миф. М., 1989. С. 263.

${ }^{16}$ Цит. по: Якобсон Р. О. Лингвистика и ее отношение к другим наукам // Он же. Избранные роботы. М., 1985. С. 372.

${ }^{17}$ См.: Леви-Стросс К. Структурная антропология. М., 1985. С. 183.
} 
мирования и предусматривающему некоторые направления его последующего развития» ${ }^{18}$. И далее французский антрополог ставит вопрос о возможности расширения методологии лингвистики на другие социальные науки. Ответ он находит тем же способом, каким Макс Мюллер постулировал связь между историческими языками и историческими религиями, а именно через выявление структурной схожести систем родства у народов определенных языковых групп: индоевропейской, африканской, океанической, североамериканской, тибетокитайской. В отличие от Мюллера, Леви-Стросс принципиально отказывается от постулирования прямой связи в пользу выявления определенных закономерностей фонетики, синтаксиса и систем родства.

Представители британской антропологии и ученики А. Рэдклифф-Брауна Э. Лич и В. Тернер в духе структурального подхода Леви-Стросса анализируют мифологию (Э. Лич) и ритуалы (В. Тернер) ${ }^{19}$. «Леви-Стросс показал, что символы общества обладают структурой, что они образуют классификационные ряды или модель для размышления и разговора о природе и социальной жизни. Отчасти по причине аналогии с лингвистикой, которая была его отправной точкой, отчасти потому, что его материалом было богатое собрание мифологий Южной Америки, Леви-Стросс проявил больший интерес к литературной, чем к ритуальной символике. Виктор Тернер перевернул эту эмфазу и, сделав это, более полно исследовал культурный и исторический контекст символики. Вследствие этого его выводы имеют значение, выходящее за рамки культурных границ народа ндембу в Замбии, где он проводил свои исследования» ${ }^{20}$. Для Тернера и Лича религия выступает как коммуникативный инструмент. Религия кодифицирует важнейшие социально-поведенческие механизмы, через которые человек и общество включают себя в культурное пространство и природный космос. Знаково-символическая природа религии является ее важнейшей характеристикой. Э. Лич показывает, что метонимия и метафора ${ }^{21}$ - языковые механизмы освоения мира, способы его упорядочивания. Религиозная символизация - это нанесение на неизвестную местность жизненного пространства маркеров, картографирование. Таким образом, религия - это культурный процесс, имеющий языковую природу. Источником маркирования жизненного пространства является трансцендентное, поскольку человек ограничен природой. Но движение от архаических религий к современным формам духовности определяется именно возможностями человеческого языка, его уровнем понятийной сложности и абстракции. Природа осознавалась очеловечиванием, а человек осознавался «оприродниванием». Смотря на природный мир, человек видел его через призму себя (антропизация), смотря на себя, человек видит себя через призму природы (натурализация). Такой разрыв между человеком и природой заполнялся религиозными формами культуры.

\section{${ }_{18}$ Леви-Стросс. Указ. соч. С. 56.}

${ }^{19}$ Классические работы по структуралистскому религиоведению: Леви-Стросс K. Тотемизм сегодня // Он же. Первобытное мышление. М., 1999; Лич Э. Культура и коммуникация. Логика взаимосвязи символов. К использованию структурного анализа в социальной антропологии. М., 2001; Тернер В. Символ и ритуал. М., 1983.

${ }^{20}$ Тернер. Указ. соч. С. 10.

${ }^{21}$ См.: Лич. Указ. соч. С. 43. 
Вяч. Вс. Иванов, исходя из тех же философских установок - структуральный характер религиозных явлений, - анализирует мифо-ритуальные системы архаических культур. Но Иванов не является учеником или последователем Леви-Стросса, так же как и Тернер, он соответствует духу лингвистической эпохи 60-70-х гг. Интересно, что Леви-Стросс, Лич, Тернер и Иванов разбирали вопрос о близнечном культе у африканских аборигенов. Иванов, в отличие от Тернера, который не принял идею оппозиционных мифологических пар, структурирующих мифологическую систему, в леви-строссовском ключе раскрывает культурные оппозиции, выражающие реальные социальные отношения: черное - белое, верх - низ, мужское - женское. С этизацией религии Н. И. Толстой связывает появление оппозиций «добро - зло», «правое - левое» ${ }^{22}$.

Символическая природа религии в представлении В. Н. Топорова, Н. И. Толстого, Вяч. Вс. Иванова и А. К. Байбурина позволяет рассматривать религию как текст культуры. Семиотизация мира в ритуале (Байбурин) или в мифе (Иванов, Топоров) происходит путем удвоения мира в его знаково-символическом выражении. Важнейшей составляющей научных исследований советских ученых было решение вопроса о механизмах семиотизации мира. Исследовав, каким образом идет процесс знаково-символического удвоения, семиотики могли проводить реконструкцию дописьменных культур по религиозным и мифологическим артефактам. Важнейшим носителем древних представлений о мире является язык и в особенности ключевые слова-концепты.

Таким образом, структурализм и семиотика в религиоведении отталкивались от следующих идей: язык гомологичен религии и обществу; религиозные явления можно рассматривать как языковые или коммуникативные явления; сам религиозный язык является носителем мировоззрений соответствующих культур.

\section{Когнитивное религиоведение}

Проблема познавательных механизмов человека и функция языка как посредника между сознанием и миром породило современную методологию в религиоведении, имеющую эмпирический характер. В когнитивном религиоведении поднимаются вопросы, которые были настойчиво поставлены еще в XIX столетии Гумбольдтом, Мюллером и Потебней. Когнитивистика рассматривает язык в двух измерениях: как самостоятельную структуру, встроенную в человеческую природу, и как когнитивный инструмент. Говоря о языке как о когнитивном инструменте, мы подразумеваем язык не как самостоятельное явление, sui generis, а как средство понимания всех ментальных процессов, происходящих в голове человека и определяющих его собственное бытие и функционирование в обществе. Процессы концептуализации и категоризации человеческого опыта реали-

${ }^{22}$ Структурно-семиотический анализ религии и мифологии представлен в классических работах: Байбурин $A$. K. Ритуал в традиционной культуре: структурно-семиотический анализ восточнославянских обрядов. СПб., 1993; Иванов Вяч. Вс. Избранные труды по семиотике и истории культуры. М., 2009. Т. 5; Толстой Н. И. Язык и народная культура. Очерки по славянской мифологии и этнолингвистике. М., 1995; Топоров В. Н. Миф. Ритуал. Символ. Образ: Исследования в области мифопоэтического: Избранное. М., 1995. 
зуются в языке, поэтому для религиоведения в когнитивистике интересны процессы категоризации религиозного опыта и анализ религиозных концептов.

Эмпирические исследования когнитивных религиоведов больше всего ассоциируются с «божественным шлемом» и нейрофизиологическими исследованиями, но это не совсем верно, так как непосредственно предметом исследования тут выступает мозг, а не религия. Изучение функционирования религиозных концептов в человеческом сознании подвигает когнитивных религиоведов обращаться к конкретным религиозным традициям и процессу формирования религиозных категорий, и в первую очередь «супранатурального агента».

М. М. Шахнович ${ }^{23}$ указывает на то, что аналогичные исследования проводились уже в советской науке (психологии и религиоведении). Объяснительные теории религии, которые предлагает эволюционная (Р. Докинз) и когнитивная (П. Буайе) психологии, имеют своими корнями отсылки к механизмам мышления, переход от образного, конкретного мышления к абстрактно-понятийному. Л. Выготский, А. Лурия, И. Франк-Каменецкий - классики психологии языка - являются мостком между натурмифологической школой религиоведения и когнитивным религиоведением.

Если для раннего Мюллера мифология была продуктом деградационистских языковых процессов, то для эволюционистских и когнитивных религиоведов религия выступает как побочный продукт психолингвистических процессов. Религия была инструментом освоения мира в супранатуральной терминологии. Такова основа критики религии Ричардом Докинзом. Для когнитивного религиоведения язык выступает как конституирующая форма ${ }^{24}$, в которой религиозный опыт схематизируется, категоризируется и концептуализируется и в дальнейшем выступает в качестве носителя религиозных представлений в культуре. Процесс категоризации и концептуализации происходит по психоментальным законам и может иметь врожденный характер, связанный с эволюционным приобретением человека.

В представленной статье автор не полностью раскрывает все точки соприкосновения лингвистики и религиоведения. Но аналитическую философию и герменевтику автор относит к философии религии, которая в современном религиоведении имеет неопределенный статус и претендует на автономность в пределах философии. Начиная М. Мюллером и заканчивая когнитивистикой,

${ }^{23}$ См.: Шахнович М. М. Когнитивная наука и исследования религии // Государство, религия и церковь в России и за рубежом. 2013. № 3. С. 32-63.

24 Лингвистические аспекты когнитивистики и когнитивного религиоведения раскрываются в следующих работах: Лакофф Дж. Женщины, огонь и опасные вещи: что категории языка говорят нам о мышлении. М., 2004; Barrett J. L. Cognitive Science of Religion: What Is It and Why Is It? // Religion Compass. 2007. Vol. 1; Idem. Cognitive Science, Religion and Theology: From Human Minds to Divine Minds. West Conshohocken (PA), 2011; Boyer P. Religion Explained: The Evolutionary Origins of Religious Thought. N. Y., 2001; Kalmykova E. Dissolving Dualism. A Tripartite Model of Cognition for Religious Truth. Uppsala, 2011; Pyysiäinen I. How Religion Works: Towards a New Cognitive Science of Religion, Cognition and Culture. Leiden, 2001. 
религиоведение получало приток свежих методологий, подходов и парадигмальных изменений со стороны лингвистики. Важно понимать, что этот процесс, возможно, не был просто механическим переносом лингвистической методологии на религиоведческую почву, но был обусловлен принципиальной схожестью языка и религиозных явлений. Именно вопрос о форме такой схожести и форме взаимодействия языка и религии порождает соответствующие выводы о природе религиозных явлений.

Ключевым для всей истории взаимоотношения языка и религии, лингвистики и религиоведения является вопрос о связи языка, мышления и мира. Все возможные ответы на такой вопрос претендуют на создание той или иной теории религии: натурмифологической, пралогической, структуралистской, семиотической, аналитической, когнитивной.

Преемственность когнитивного религиоведения от натурмифологической школы показывает, что лингвистическое изучение религии в широком понимании и дисциплинарных проявлениях (социо-, этно-, культур-, психолингвистика, дискурс-анализ) открывает широкие перспективы для изучения религиозных феноменов, и религиоведам следует обращать внимание на новые достижения языковедения и филологии.

Ключевые слова: языковедение, сравнительная методология, М. Мюллер, К. Леви-Стросс, Вяч. Вс. Иванов, структурализм, семиотика, когнитивистика, мифология.

\section{The Linguistic Roots of Religious Studies}

\section{G. TSELKOVSKY}

The author discusses how linguistics influenced the formation of the methodology and the theory of religious studies. Changes in religious paradigms were connected with the following new theories in linguistics: comparative methodology, structuralism, and cognitive linguistics. It was these three branches of linguistic studies which were most influential for the formation and later development of religious studies. The author asks precisely why it was that linguistics constituted the source of global changes in the methodology of religious studies. According to the author, this fundamental role was played by the understanding of language and its rapport with religion. By examining both language and religion together, one may study religious phenomena through the prism of linguistic phenomena. Models for combining religion and language include the following: 1) religion as a linguistic phenomenon; 2) religion as the product of linguistic processes; 3 ) religion and language are homologous phenomena; 4) religion is formed by means of linguistic instruments. All this allows us to understand the history of religious studies in rapport with the development of linguistics. The author demonstrates that the problem of the rapport linking language and thought helped constitute the tie between 
linguistics and religious studies. It unifies in itself all the various linguistic theories of religion: nature-mythological, structuralist, and cognitive. The author then discusses the various attainments of each of these theories. Comparative-historical linguistics begets the comparative and nature-mythological theory in religious studies. Structural linguistics and semiotics explains the symbolic nature of religion and its communicative character. The appearance of extra-linguistic science will allow religious studies to define new subjects of study, such as the link uniting religion language and the religious group (ethno-linguistics and socio-linguistics) or to reveal the variables of religious experience (psycho-linguistics).

Keywords: linguistics, comparative methodology, M. Müller, Claude Lévi-Strauss, Vyacheslav Ivanov, stucturalism, semiotics, cognitive studies, mythology.

\section{Список литературы}

1. Ayer A. The Problem of Knowledge. L., 1956.

2. Barrett J. L. Cognitive Science of Religion: What Is It and Why Is It? // Religion Compass. 2007. Vol. 1. № 6. P. 768-787.

3. Barrett J. L. Cognitive Science, Religion and Theology: From Human Minds to Divine Minds. West Conshohocken (PA), 2011.

4. Boyer P. Religion Explained: The Evolutionary Origins of Religious Thought. N. Y., 2001.

5. Kalmykova E. Dissolving Dualism. A Tripartite Model of Cognition for Religious Truth. Uppsala, 2011.

6. Muller F. M. Three Lectures on the Science of Language and its Place in the General Education delivered at the Oxford University Extension Meeting. Chicago, 1899.

7. Philips D. Z. Religion without Explanation. Oxford, 1977.

8. Plantinga A. The Warrant Christian Belief. N. Y., 2000.

9. Pyysiäinen I. How Religion Works: Towards a New Cognitive Science of Religion, Cognition and Culture. Leiden, 2001.

10. Usener H. Götternamen. Bonn, 1896.

11. Walterstorf $N$. Divine Discourse: Philosophical Reflections on the Claim that God Speaks. Oxford, 1997.

12. Байбурин A. K. Ритуал в традиционной культуре: структурно-семиотический анализ восточнославянских обрядов. СПб., 1993.

13. Гердер И. Г. Идеи к философии истории. М., 1977.

14. Гумбольдm B. О различии строения человеческих языков и его влиянии на духовное развитие человечества // Вильгельм фон Гумбольдт. Избранные труды по языкознанию. М., 2000. С. 37-301.

15. Иванов Вяч. Вс. Избранные труды по семиотике и истории культуры. М., 2009.

16. Лакофф Дж. Женщины, огонь и опасные вещи: что категории языка говорят нам о мышлении. М., 2004.

17. Леви-Стросс К. Структурная антропология. М., 1985.

18. Леви-Стросс K. Тотемизм сегодня // Он же. Первобытное мышление. М., 1999. C. 37-111.

19. Лич Э. Культура и коммуникация. Логика взаимосвязи символов. К использованию структурного анализа в социальной антропологии. М., 2001.

20. Мюллер Ф. М. Введение в науку о религии. Четыре лекции, прочитанные в Лондонском Королевском институте в феврале-марте 1870 года. М., 2002.

21. Потебня А. А. Слово и миф. М., 1989. 
22. Самарина T. С. Методологические основы религиоведческого исследования в концепции Фр. Хайлера // Вестник ПСТГУ І: Богословие. Философия. 2014. Вып. 1 (45). C. 57-71.

23. Тернер В. Символ и ритуал. М., 1983.

24. Толстой Н. И. Язык и народная культура. Очерки по славянской мифологии и этнолингвистике. М., 1995.

25. Топоров B. Н. Миф. Ритуал. Символ. Образ: Исследования в области мифопоэтического: Избранное. М., 1995.

26. Шахнович М. М. Когнитивная наука и исследования религии // Государство, религия и церковь в России и за рубежом. 2013. № 3. С. 32-63.

27. Элиаде М. Ностальгия по истокам. М., 2006.

28. Яблоков И. Н. Религиоведение: Учеб. пособие. М., 2004.

29. Языки как образ мира. М.; СПб., 2003.

30. Якобсон Р. О. Лингвистика и ее отношение к другим наукам // Он же. Избранные работы. М., 1985. С. 369-421. 